\title{
Factors associated with undergraduate alcohol use
}

\author{
P. S. PARFREY \\ Department of Social and Preventive Medicine, University College, Cork, Ireland
}

\begin{abstract}
SUMMARY
To examine cigarette, alcohol, and drug use among undergraduates in Cork a precoded questionnaire was mailed to one in seven (458) students, chosen systematically. The response rate was $97 \%$. Twenty per cent of males and $36 \%$ of females do not drink, whereas $52 \%$ of males and $17 \%$ of females are social drinkers or occasional drunks. Student patterns of drinking behaviour were significantly associated with sociocultural factors, such as leisure money available, belief in a God, and frequency of attendance at religious services. Current cigarette use, experience of marijuana, and attitude to future marijuana use, to the opposite sex drinking, and to the misdemeanour considered most serious also had significant associations with alcohol-related behaviour. It appears that peer group pressures, as illustrated by the proportion of close friends drinking and sibling drinking, have a greater influence on student drinking behaviour than family-related factors such as parental drinking and parental knowledge of drinking. The effect of ambivalent attitudes towards alcohol use, demonstrated by the age at introduction and the place of introduction to alcohol, may suggest that a more relaxed attitude to alcohol should be adopted.
\end{abstract}

\section{INTRODUCTION}

In 1970 there were well over 200,000 alcoholics in need of hospitalization in Great Britain (Davies and Stacey, 1972). In Ireland there is a special problem with excessive drinking. While there is a declining percentage of total consumer spending on food and non-alcoholic beverages, the percentage spent on alcoholic drink in Ireland is steadily increasing, despite the fact that there is an unusually high proportion of total abstainers, especially in the female population (The Irish Council of Alcoholism, 1973).
An increasing number of young people (aged 30 years or less) are experiencing difficulties with alcohol. This must be of concern in view of the particularly poor prognosis for young people (Davies and Stacey, 1972). A study of drinking among 18 to 21-year-olds in Dublin disclosed a disquieting increase in alcohol consumption by them and also by their parents (Fitzpatrick, 1972)

The harsh medical realities of cigarette smoking alcoholism, and drug abuse sometimes obscure? analyses of the personality and environmental factors involved in intoxicant use. Ireland may be classified as having an ambivalent culture as far aso alcohol is concerned (Fitzpatrick, 1972). On the one hand drinking is integrated into the social and economic framework of the culture, while on the other hand the emergence of a Catholic Total Abstinence Association introduces an opposing value system. In Ireland, male and female atti udes to alcohol also differ and the relationship of parental drinking practices and attitudes to those of their children adds to the confusion concerning the use of alcohol in Irish society.

A study was undertaken in University College, Cork to assess the extent and prevalence of intoxicant use (cigarettes, alcohol, and drugs) among undergraduates, and to investigate the various factors associated with their use.

\section{MethodS}

To examine cigarette, alcohol, and drug use among undergraduates in Cork a precoded questionnaire was devised and mailed to one in seven undergraduates. The population sampled in the survey amounted to 3,207 students. The sample was chosen systematically from student class lists of names in alphabetical order, stratified into faculties. The response rate to the questionnaire was $97 \%, 444$ out of 458 students returned the 
completed forms. The questionnaires were mailed during March 1973, and two subsequent follow-ups ensured the high response rate.

The questionnaire was divided into three parts and contained 53 questions. The first part explored the respondents' personality and sociocultural background, including some questions on cigarette use. The second part was concerned with respondents' experience of and attitudes to alcohol, while the final part examined the students' drug-taking experiences.

Logical consistency checks confirmed the validity of the data, which were analysed by computer following editing for accuracy and uniformity. The $\chi^{2}$ test was the main test of significance.

Seven patterns of drinking behaviour (derived from Mann (1952)) were described in the questionnaire, the student marking off the pattern he considered most appropriate to his drinking behaviour. These categories were (i) 'Pioneer' (member of a Catholic Total Abstinence Association); (ii) nondrinker (does not drink but nota pioneer); (iii) occasional drinker (drinks socially a few times a year); (iv) moderate drinker (drinks when drinking is in order but never more than two to three drinks); (v) social drinker (does not limit consumption but rarely drinks to drunkenness); (vi) occasional drunk (indulges in short periods of drinking to drunkenness at sporadic intervals); (vii) regular heavy drinker. Only four students (all males) admitted to being regular heavy drinkers. Owing to their insignificant number they were not included in the subsequent analysis. The factors analysed include (i) demography; (ii) socioculture; (iii) intoxicant use and attitudes; (iv) family; (v) peer groups; (vi) circumstances of first drink.

\section{RESULTS}

The analyses are based on the replies from 265 out of 274 males and 179 out of 184 females sampled who completed the questionnaires. Any minor discrepancies in the ensuing tables are due to incomplete answering of some questions by respondents. A higher proportion of females (36\%) than of males $(20 \%)$ do not drink, whereas a higher proportion of males $(52 \%)$ than of females $(17 \%)$ are social drinkers or occasional drunks. The distribution of males and females by their pattern of drinking behaviour is shown in Table $\mathrm{I}$.

\section{Age}

Although higher proportions of both males and females aged 17-20 years do not drink and smaller proportions are social drinkers compared with
TABLE I

PATTERNS OF DRINKING BEHAVIOUR RELATED TO SEX

\begin{tabular}{l|rr|rr|rr}
\hline & \multicolumn{2}{|c|}{ Male } & \multicolumn{2}{c|}{ Female } & \multicolumn{2}{c}{ Total } \\
\cline { 2 - 7 } & $\mathrm{N}$ & $\%$ & $\mathrm{~N}$ & $\%$ & $\mathrm{~N}$ & $\%$ \\
\hline $\begin{array}{l}\text { Pioneer } \\
\text { Nondrinker }\end{array}$ & 14 & 5 & 33 & 19 & 47 & 11 \\
$\begin{array}{c}\text { Occasional } \\
\text { drinker }\end{array}$ & 18 & 15 & 30 & 17 & 69 & 16 \\
$\begin{array}{c}\text { Moderate } \\
\text { drinker }\end{array}$ & 51 & 19 & 35 & 20 & 86 & 20 \\
$\begin{array}{c}\text { Social } \\
\text { drinker }\end{array}$ & 101 & 38 & 27 & 15 & 128 & 29 \\
$\begin{array}{c}\text { Occasional } \\
\text { drunk }\end{array}$ & 37 & 14 & 4 & 2 & 41 & 9 \\
$\begin{array}{c}\text { Regular } \\
\text { heavy } \\
\text { drinker }\end{array}$ & 4 & 2 & 0 & 0 & 4 & 1 \\
\hline Total .. & 264 & 100 & 177 & 100 & 441 & 100 \\
\hline
\end{tabular}

those 21 years or older, the associations between age and patterns of drinking behaviour were not significant.

Tables II and III illustrate the various factors significantly associated with male and female patterns of drinking behaviour.

\section{Sociocultural Factors}

Leisure Money. Among male and female students there is a decrease in the proportion of pioneers and nondrinkers and an increase in the proportion of social drinkers and occasional drunks, as the amount of leisure money available increases.

ReLigion. Only $5 \%$ of the sample had no belief in a God, a further $8 \%$ were not sure of their belief, and the remainder ( $87 \%$ ) believe in a God. As expected, the vast majority of pioneers $(97 \%)$ believed in a God, as did very high proportions of nondrinkers $(93 \%)$. However, relatively low proportions of female social drinkers $(78 \%)$ and of male occasional drunks ( $73 \%$ ) believed in a God. This tendency of believers not to drink is illustrated by the significant association between student patterns of drinking behaviour and frequency of attendance at religious services. With an increase in the frequency of drinking the proportion of males and females who attend religious services more than once a week decreases and the proportion who attend services infrequently, or never, increases.

\section{Intoxicant Use AND Attitudes}

Cigarette Smoking. A light smoker was defined as one who smokes 1-10 cigarettes a day and a heavy smoker as one who smokes more than 10 cigarettes a day. Sixty-four per cent of males and $72 \%$ of females in this sample were nonsmokers, 
TABLE II

FACTORS ASSOCIATED WITH MALE PATTERNS OF DRINKING BEHAVIOUR

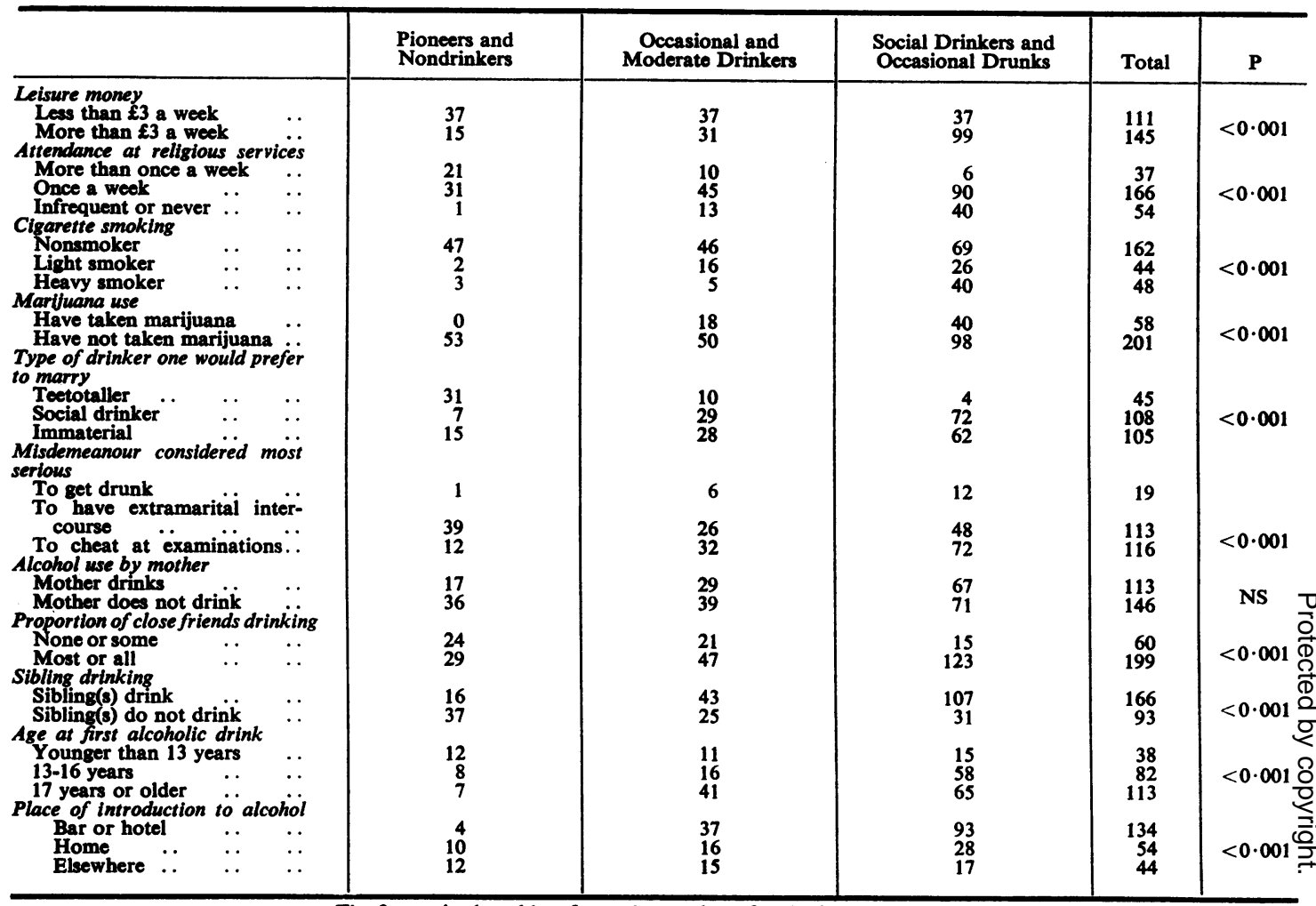

The figures in the table refer to the number of males in each category.

whereas $19 \%$ of males were heavy smokers, only $6 \%$ of females had similar smoking habits. Very high percentages of males and females who do not drink and relatively low percentages of social drinkers and occasional drunks were nonsmokers. Furthermore, among males, relatively high percentages of social drinkers and occasional drunks were heavy smokers.

DRUG USE. Twenty-two per cent of males and $13 \%$ of females admitted to taking marijuana at least once. From Tables II and III it can be seen that no pioneer or nondrinker had taken marijuana and that relatively high proportions in the heavier drinking categories had taken marijuana at least once. A similarly significant pattern of drinking behaviour existed among male and female students who would take marijuana if the opportunity arose.

Atritude to Opposite Sex Drinknng. The polarized attitude of drinkers and nondrinkers towards drinking in the opposite sex is illustrated by analysis of student attitudes towards the type of $\frac{\AA}{\varnothing}$ drinker they would like to marry. The majority of students who do not drink would like to marry a teetotaller, and relatively high proportions of students who drink would like to marry a social drinker. A similar significant association was obtained on analysis of student patterns of drinking behaviour and attitudes to boy/girl friend's drinking.

Misdemeanour Considered Most Serious. Only $8 \%$ of students considered getting drunk more serious than having sexual intercourse outside marriage or than cheating at examinations. A higher proportion of males $(47 \%)$ than of females $(38 \%)$ considered cheating at examinations most serious, and a higher proportion of females (54\%) than of males $(45 \%)$ felt having sexual intercourse outside marriage most serious. Pioneers and nondrinkers tended to feel that extramarital intercourse was the most serious misdemeanour, whereas students in the less moderate drinking categories tended to consider cheating at examinations most serious. 
TABLE III

FACTORS ASSOCIATED WITH FEMALE PATTERNS OF DRINKING BEHAVIOUR

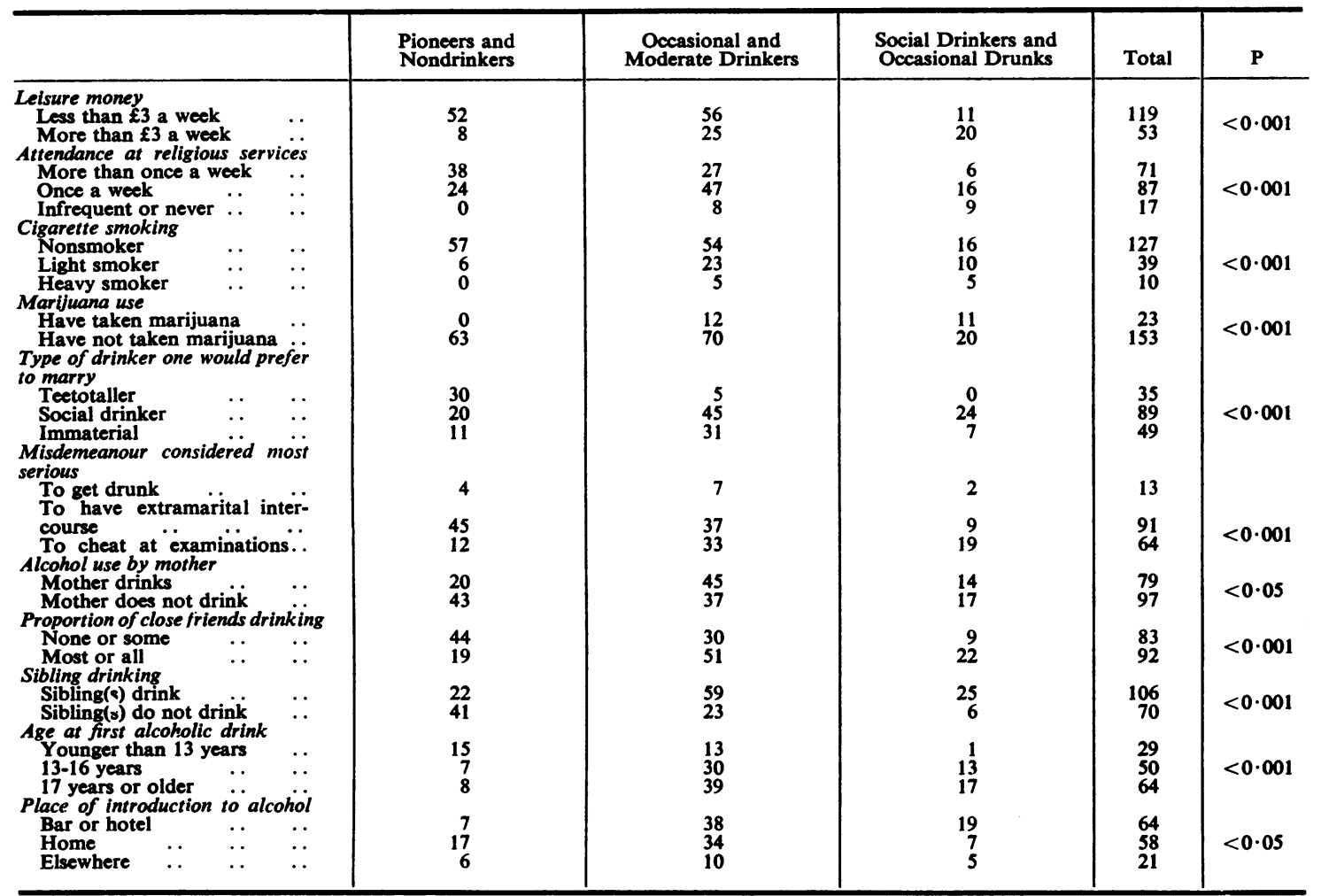

The figures in the table refer to the number of females in each category.

\section{FAMILY FACTORS}

Parental Drinking. Sixty-nine per cent of respondents' fathers and $44 \%$ of their mothers drank but student patterns of drinking behaviour were significantly associated only with use of alcohol by mother. The association between male drinking behaviour and alcohol use by mother was not significant but for females a significant association was obtained. In fact a high proportion of females who drink have mothers who drink.

Parental Knowledge of Drinking. Seventy per cent of males who drank felt their fathers knew they drank as compared with $65 \%$ of females. Eighty per cent of males who drank and $68 \%$ of females who drank considered that their mother had knowledge of their drinking. The significant associations between parental knowledge of drinking and male patterns of drinking behaviour showed that very low proportions of occasional drinkers felt their mother or father knew they drank.
Twenty-eight per cent of male occasional drinkers considered their fathers knew they drank, and $50 \%$ of them felt their mothers had knowledge of their drinking. The association between parental knowledge of drinking and female pattern of drinking behaviour was not significant.

\section{Peer Group Pressures}

Close Friends. Seventy-seven per cent of males and $53 \%$ of females considered that most or all their friends drink. From Tables II and III it may be observed that relatively high proportions of social drinkers and occasional drunks considered all or most of their close friends drink, and relatively high proportions of students who do not drink felt none or some of their friends drink. However, $53 \%$ of males and $49 \%$ of females felt they had been encouraged by their friends to drink. The encouragement of students by their friends to drink was not significantly associated with student patterns of drinking behaviour. 
Sibling Drinking. Sixty-two per cent of students had sibling(s) who drink, a variable associated with student drinking behaviour. Low percentages of students who do not drink and high percentages in the less moderate categories had sibling(s) who drink.

\section{Circumstances of First Drink}

AGE. Eighteen per cent of students took their first alcoholic drink when younger than 13 years of age, $35 \%$ did so between 13 and 16 years, and the majority ( $47 \%$ ) did so when 17 years or older. Among both males and females who took their first drink when in their later teens, the proportion of students who do not drink is relatively small. Relatively small proportions of males and females who took their first drink when younger than 13 years are now in the heavier drinking categories.

Place. Fifty-three per cent of students were introduced to alcohol in a bar or hotel and a further $30 \%$ obtained their first drink at home. Analysis of student patterns of drinking behaviour and place of introduction to alcohol revealed that among males and females intioduced to alcohol at home or elsewhere, other than in hotels or bars, relatively high proportions do not drink and relatively low proportions are social drinkers or occasional drunks. In contrast, among males introduced to alcohol in a bar or hotel relatively low proportions do not drink and relatively high proportions are social drinkers or occasional drunks.

\section{Discussion}

Patterns of affluence, religious beliefs, and intoxicant use have undergone great change in recent decades. Davies and Stacey (1972), in a study of adolescent drinking carried out in Glasgow, concluded that an increasing amount of available pocket money was independently related to both increasing age and to increasing alcohol consumption. A similar association was observed in the present study.

The religious influence on Cork male students to abstain is not as strong as on females, as demonstrated by the fact that $5 \%$ of males and $19 \%$ of females were total abstainers (pioneers). Furthermore, in Cork significant associations were obtained between belief in a God, frequency of attendance at religious services, and student patterns of drinking behaviour. In contrast, Davies and Stacey (1972) found a small negative correlation between increasing Church attendance (regardless of which denomination) and their drinking index.
In recent years, particularly in the last decade, new patterns of drug use have developed (World Health Organisation, 1973). In this study significant associations were obtained between marijuana use, attitude to future marijuana use, cigarette use, and patterns of drinking behaviour. A desire for acceptance and social interaction in a particular peer group may result in starting and maintaining the use of drugs if some influential members of that group happen to be intermittent or regular users, an idea supported by the associations between drinking behaviour, proportion of close friends drinking, and marijuana use.

Veevers (1971) demonstrated that respondents' attitudes towards the drinking of alcoholic beverages are highly associated with their reported drinking behaviour. He also felt that the simpler approaches in the attitude field yield results highly comparable with more complex scaling methods and correlate well with reported drinking behaviour. In the present study some attitudes to drinking were ascertained by questions on student attitudes to friends of the opposite sex drinking. A polarized attitude of drinkers and non-drinkers towards their boy/girl friend's or future marriage partner's drinking was observed.

It is of interest that only $8 \%$ of the sample considered getting drunk more serious than having extramarital intercourse or than cheating at examinations. Students who adhered to the traditional mores of Irish society-who believed extramarital intercourse was the most serious misdemeanour-tended not to drink, whereas students who considered cheating at examinations most serious, viewing perhaps honesty and sincerity as more important than the traditional morals, tended to drink immoderately.

Family background influences many adult patterns of behaviour. A significant association was observed between use of alcohol by mother and the drinking practices of their daughters. Forslund and Gustafson (1970), in a study of highschool seniors in New Mexico, observed that the mothers' drinking practices had a significant effect on the drinking practices of both sons and daughters but were stronger on daughters. The Cork study noted little influence of fathers' drinking behaviour on their offspring. However, in the New Mexico study, although fathers' drinking behaviour influenced that of their daughters, it had little effect on the drinking practices of their sons.

Over two-thirds of all 18 to 21-year-olds interviewed by Fitzpatrick (1972) in a Dublin housing estate felt obliged at the time to hide from their 
parents the fact that they had taken a drink, although in Cork smaller proportions felt their parents did not know they drank. This apparent need to hide their drinking behaviour may suggest that the peer group is important in helping young people to gain support for their new behaviour pattern-drinking. The ambivalence towards alcohol use in Ireland is further illustrated by the higher proportions of females than males who claimed that their parents did not know they drink, suggesting that the conservative attitude of the older generation in Ireland against women drinking could force the young woman to hide her drinking behaviour from her family.

In Cork the significant associations between close friends drinking, sibling drinking, and student patterns of drinking behaviour suggest strong peer group pressures to drink. These peer group associations also support Meir's carefully reasoned argument, quoted by Forslund and Gustafson (1970), that 'the school context and school-based peer associations play an increasingly important part in shaping the youth's perspectives'.

An examination of the age at which subjects report first taking alcohol among Scottish teenagers (Davies and Stacey, 1972) showed that most adolescents remember first experiencing alcohol between the ages of 13 and 14 years. In Cork about $9 \%$ took their first drink between 11 and 15 years, illustrating the effect of the Confirmation Pledge of abstinence for religious reasons in encouraging adolescents to abstain from 12 years onwards. The ambivalence created by this abstinence is further illustrated by the fact that most first drinks were taken outside the home in a bar or hotel. In the Glasgow survey, $47 \%$ of males and $40 \%$ of females got their first taste of alcohol from their parents, whereas among Cork undergraduates $23 \%$ of males and $41 \%$ of females got their first drink at home, an observation which may suggest that the majority of parents do not wish to introduce their children to alcohol.

Student pattern of drinking behaviour was associated significantly with age at taking the first drink and place of introduction to alcohol. Parents who treat moderate alcohol consumption as acceptable, and do not retain an ambivalent attitude to alcohol use, may produce a moderate and controlled attitude to alcohol use among their children. However, the tendency to heavier drinking is increased by a later age of starting to drink and, among males, by introduction to alcohol in a bar or hotel. These facts may suggest that a health education campaign for complete abstinence when young may meet with little success, particularly in a society with ambivalent attitudes towards alcohol use, and indeed may support Lord Errol and his committee (Leading Article, Lancet, 1973) who believe that Britain should adopt a more relaxed attitude to alcohol.

I thank Professor J. P. Corridan, Professor of Social and Preventive Medicine in University College, Cork, for the supervision, patience, and criticisms he offered throughout the project. I wish to thank Dr. T. M. F. O'Donovan, of the Department of Statistics, the staffs of the Computer Science and the various academic and administrative departments, who gave their assistance. Finally, thanks are due also to my student colleagues without whose response the project would never have been completed.

\section{REFERENCES}

DAviEs, J. and StACEY, B. (1972). Teenagers and Alcohol, Office of Public Censuses and Surveys, Social Survey Reports. HMSO, London.

FITZPATRICK, J. (1972). Drinking among young people in Ireland. Soc. Studies, 1, 51.

Forslund, M. A. and Gustafson, T. J. (1970). Influence of peers and parents and sex differences in drinking by high-school students. Quart. J. Stud. Alcohol, 31, 868.

The Irish National Council of Alcoholism (1973). Report to the Minister for Health. General Statistics Office, Dublin.

LEAding ARTicle (1973). Young drinkers. Lancet, 1, 142.

Mann, M. (1952). Primer on Alcoholism, p. 60. Victor Gollancz, London.

Veevers, J. E. (1971). Drinking attitudes and drinking behavior; an exploratory study. J. Soc. Psychol., 85, 103.

World Health Organisation (1973). Youth and Drugs. Wld Hlth Org. techn. Rep. Ser. No. 516. WHO, Geneva. 